\title{
REPERCUSSÕES DA PANDEMIA DO NOVO CORONAVIRUS SOBRE OS PROFISSIONAIS DE SAÚDE NO HOSPITAL DO SERVIDOR PÚBLICO MUNICIPAL, OPÇÕES TERAPEUTICAS NA VISÃO DAS PRÁTICAS INTEGRATIVAS E COMPLEMENTARES.
}

\author{
Suzin, Joseli Beatriz ${ }^{52}$; Santomauro, Augusto Cezar ${ }^{53}$; Aleixo, Paloma ${ }^{54}$.
}

\section{INTRODUÇÃO}

A emergência de saúde pública com a pandemia do novo Coronavírus trouxe situações de grande sofrimento para indivíduos, famílias e comunidades inteiras. Em um primeiro momento a saúde física e o combate ao agente patogênico, são a principal atenção dos gestores e profissionais da saúde e por isso os impactos com a saúde mental e o bem estar das pessoas é usualmente relegado a um segundo plano.

Conduto, medidas para reduzir o impacto psicológico não podem ser negligenciadas, principalmente quando informações dúbias ou mesmo falsas levam à insegurança e ao medo, causando pânico. Em linhas gerais, pesquisas sobre epidemias mostram que o número de pessoas cuja saúde mental é afetada tende a ser superior aos casos de infecção, além do que esta memória em longo prazo pode afetar a saúde mental por mais tempo e com maior prevalência do que os impactos psicossociais e econômicos (ORNELL, 2020).

Corroboram com esta afirmação (DANZMANN, 2020) entendendo que as conseqüências, frente a pandemia pelo Coronavírus e os múltiplos fatores que a cercam, não se restringem somente ao momento atual, mas também após ela se extinguir, levando a impactos a longo prazo.

As doenças mentais trazem uma diminuição da saúde física e da expectativa de vida, sem considerar o estigma que ela causa, trazendo um impacto a todos a sua volta.

É fato que foram os profissionais da saúde os que mais sofrem diretamente com a pandemia, pois ficaram sobrecarregados e impedidos de não se expor, como a orientação a ser seguida

\footnotetext{
${ }^{52}$ Médica Acupunturiatra, Coordenadora do Setor de Práticas Integrativas do HSPM.

${ }^{53}$ Médico Cardiologista, Voluntário do setor de Práticas Integrativas e Complementares do HSPM.

${ }^{54}$ Farmacêutica Responsável do laboratório ALKHEMY-Lab By Joel Aleixo.
} 
pela maioria. Estudos produzidos em situações semelhantes (CHUA, 2004), reportaram que $89 \%$ dos trabalhadores que se encontravam em situações de alto risco no trabalho, apresentavam sintomas negativos, como cansaço, preocupação com a saúde, temor ao contato social. Entre esses sintomas, foram descritos altos níveis de estresse e sintomas de depressão e ansiedade. E não foi diferente com os profissionais do Hospital do Servidor Público Municipal de São Paulo - HSPM, logo no início da pandemia foi observado que os funcionários tanto os que tinham contato direto com pacientes, como os funcionários de apoio, encontravam-se em estado de alerta.

O número total de funcionários que, procuraram as práticas integrativas foi 122 sendo 103 do sexo feminino e 19 do sexo masculino.

A média da idade dos funcionários para o sexo feminino foi de 46 anos, variando de 19 a 73 anos e para o sexo masculino foi de 50 anos variando de 27 a 65 anos.

Considerando a área de trabalho dos funcionários tivemos $72 \%$ do atendimento direto ao paciente, como técnicos de laboratório, enfermeiros, biólogos, dentistas e médicos e $28 \%$ da área administrativa.

Em relação à freqüência dos sentimentos relatados pelos funcionários, que participaram da ação, durante o pico da pandemia do covid19, foi:

\begin{tabular}{|c|c|}
\hline Ansioso & 72 \\
\hline Inseguro & 38 \\
\hline Com medo & 32 \\
\hline Desanimado & 21 \\
\hline Sente-se bem com auto cuidado, agitado,tenso, cansado, desprotegido & 19 \\
\hline Enfrenta o desafio, mas com receio, ou com ansiedade, ou com resguardo. & 15 \\
\hline Nervosismo, abandono e solidão familiar & 12 \\
\hline Equilibrado, disposto prestativo, adaptado, enfrenta bem o desafio, tranqüilo & 10 \\
\hline
\end{tabular}

As primeiras intervenções para o controle desses sintomas, sugeridas internacionalmente, se restringiam a equipes de intervenção psicológica e psiquiátrica (Li, 2020).

Mas, são múltiplos os recursos terapêuticos baseados em conhecimentos tradicionais que podem prevenir ou mesmo tratar doenças, como as Práticas Integrativas e Complementares - PICS (Brasil. Ministério da Saúde, 2018). 
Recomendações do Conselho Nacional de Saúde (CNS), instância deliberativa e permanente do Sistema Único de Saúde (SUS); aprovou a Deliberação 41/2020, uma recomendação para o Ministério da Saúde, conselhos estaduais e municipais de Saúde e do Distrito Federal pela inclusão e divulgação de Práticas Integrativas e Complementares em Saúde (PICS) na assistência ao tratamento para combater a Covid-19 (Conselho Nacional de Saúde, 2020).

O Conselho Nacional de Saúde e a Comissão Intersetorial de Promoção, Proteção, Práticas Integrativas e Complementares em Saúde (CIPPSPICS) do CNS entendem que: "Neste momento, em que não há ainda medicação para a cura, vários profissionais estão utilizando as práticas integrativas como forma de complementar a assistência" (Conselho Nacional de Saúde, 2020). Pesquisas mostram que as Práticas Integrativas apresentam impactos positivos na saúde dos usuários nas dimensões psicológica, física e emocional e podem ajudar a diminuir o estresse do trabalho (DACAL, 2018).

\section{OPÇÕES TERAPÊUTICAS}

Diante da situação de enfrentamento ao Coronavirus com que a Saúde vem lidando, as Práticas Integrativas e Complementares - PICs do HSPM surge como opção terapêutica e através delas, no caso a terapia floral e a aromaterapia, pôde dar ajuda prática a todos os funcionários que nos procuraram.

O uso de óleos essenciais e o conhecimento de suas propriedades curativas remontam a milênios, com as civilizações egípcia e chinesa. Os romanos, e mais tarde também os árabes, aperfeiçoaram a prática das civilizações anteriores passando a utilizá-los de diversas formas (DIAS, 2013).

Os óleos essenciais são utilizados para trazer bem-estar físico, mental e emocional, estudos mostram que existem ligações entre olfato e sentimentos. Ao inalar os aromas, os receptores olfativos enviam estímulos nervosos diretamente para o sistema límbico, região do sistema nervoso que é responsável pelas emoções. Podendo ocorrer reações nervosas às propriedades aromáticas, e modificação do humor ou afeto das funções psíquicas (MACHADO 2011)

Os óleos essenciais fazem parte do metabolismo secundário das plantas e são sintetizados com a finalidade de proteção, defesa e reprodução da planta aromática. São produzidos em vários elementos constituintes da planta como pelas flores, folhas, talos, caule, 
pecíolo, casca, raiz, glândulas etc. As principais famílias que produzem são as lauráceas, mirtáceas, labiadas, compostas, rutácease e umbilíferas. (Andrei 2005; pg11,4).

Etmologicamente, a palavra "aromaterapia” é composta de aroma, significando fragrância e terapia significando tratamento. A aromaterapia é um ramo da Fitoterapia, que através do uso dos óleos essenciais das plantas aromáticas, pretende promover saúde e bem estar às pessoas, uma vez que diferentes aromas acionam respostas específicas no cérebro levando a resultados próprios (Abrão Neto, 2018).

As primeiras práticas na produção de incensos através da queima de resinas e gomas vegetais são identificadas nas pesquisas antropológicas e paleontológicas. Segundo Kathi Keville e Mindy Green entre os anos 7.000 e 4.000 a.C., gorduras e óleos de sândalu e de oliva eram associados à plantas aromáticas na produção das primeiras pomadas neolíticas (Abrão Neto, 2018).

Hipócrates, chamado "pai da medicina", usava na sua prática médica a queima de óleos essenciais -fumigações- para diversos tratamentos.

Avicena foi um médico persa e alquimista, filósofo, cientista que inventou a destilação, serpentina refrigerada, para obtenção dos óleos essenciais (CORRÊIA, 2010). Alquimistas da Alemanha, no século XVI aperfeiçoaram o processo de destilação (Abrão Neto, 2018).

O químico francês René Maurice Gattefossé, por volta de 1920, cria o termo aromaterapia que descreve o uso prático dos óleos essenciais para a melhora da saúde física, mental-emocional e espiritual. Reuniu informações importantes das propriedades antissépticas desses óleos (BERWICK, 1998) (KIPLING, 1993).

Nicholas Culpepper, médico, botânico, herbalista com seus dedicados estudos catalogou centenas de ervas medicinais (CORRÊIA, 2010).

Jean Valnet, médico francês, durante a Segunda Guerra Mundial, usou óleos essenciais para tratar processos infecciosos e dolorosos nos soldados feridos (KELLER, 2003).

Marguerite Maury, farmacêutica bioquímica, criou as técnicas de uso dos óleos essenciais nas massagens permitindo a absorção cutânea dos mesmos (KIPLING,1993) (DAVIS, 1996).

Nessa perspectiva, o setor de Práticas Integrativas e Complementares do HSPM que já desenvolvia um trabalho com a Terapia Floral e Aromaterapia juntamente com seus colaboradores, e, em parceria com o laboratório ALKHEMY-Lab By Joel Aleixo, que agregando o objetivo de complementar as medidas preventivas na pandemia, cooperou com o 
fornecimento do seu produto aromático Imunosinergia, um produto pronto e de uso inalatório e também de absorção pela pele, contendo os óleos essenciais de Alecrim (Rosmarinus officinalis), Eucalipto (Eucalyptus globulus), Hortelã-Pimenta (Mentha piperita), Lavanda (Lavandula officinalis), Tea-tree (Melaleuca alternifolia). A associação desses óleos essenciais traz uma sinergia dos seus princípios ativos como pineno, limoneno, linalol, eucaliptol, terpineol, 4-terpineol, sesquiterpenos, citronelal, eucaliptol, eugenol, pineno, canfeno, eucaliptol, cânfora, geraniol, lavandulol, acetato de lavandila, resultando em efeitos antiinflamatório, analgésico, anti-séptico, adstringente, expectorante, estimulante do sistema imunológico, bronco dilatador, descongestionante, restaurador do equilíbrio mental, harmoniza os sentimentos, traz a consciência da realidade e paz.

A orientação de uso foi aplicar duas borrifadas na palma das mãos, fechá-las em forma de concha inspirando pelo nariz e expirando pela boca de forma calma e profunda por algumas vezes. E aplicar duas borrifadas na região torácica na face anterior e posterior e massagear 6 vezes ao dia.

Sendo assim, iniciou-se a distribuição, dessa Aromaterapia, a todos os funcionários do hospital que, assim o quisessem, sejam os que estavam na linha de frente ao combate do COVID - 19, como também os funcionários que embora não estivessem na linha de frente, sentiam-se inseguros, com medo os que apresentavam sofrimento e desequilíbrio emocional que resultavam desenvolvimento de possíveis disfunções físicas e psicológicas.

\section{CONCLUSÃO}

Como comprovado, as Práticas Integrativas podem ajudar a diminuir o estresse do trabalho, principalmente daqueles que estão sofrendo diante dos fatores de riscos aos quais estão expostos, e também frente ao medo e angústia que todos estamos vivendo.

A aromaterapia pode ser oferecida como suporte terapêutico aos profissionais de saúde que cuidam de pessoas com Covid-19 e à comunidade em geral, acometida ou não pela doença, em quarentena domiciliar ou só em isolamento social, garantindo um clima de tranqüilidade, equilíbrio emocional, além do fortalecimento de alguns sistemas, como o respiratório e o imunológico.

É importante entender como o funcionário da saúde está vivenciando a experiência de uma pandemia, como se sente e se comporta em relação ao seu trabalho, família e 
pessoalmente com tantas incertezas. Dessa forma, promover ações dentro das PICs que venham trazer conforto, equilíbrio e bem estar físico mental e emocional.

\section{REFERÊNCIA BIBLIOGRÁFICA}

Abrão Neto, E; Curso básico de aromaterapia - projeto Renascer Reiki. Apostila complementar ao curso. 2018.

Andrei P; Del Cumone AP. Aromaterapia e suas aplicações. Centro Universitário São Camilo. 2005; 11(4).

Brasil. Ministério da Saúde. (2018). Política Nacional de Práticas Integrativas e Complementares (PNPIC) no SUS. Portaria $\mathrm{n}^{\mathrm{o}}$ 702/2018. Disponível em: http://189.28.128.100/dab/docs/portaldab/publicacoes/manual_implantacao_servicos_pics.pdf

Conselho Nacional de Saúde, 2020, disponível em: https://conselho.saude.gov.br/ultimasnoticias-cns/1196-covid-19-cns-recomenda-divulgacao-praticas-integrativas-e-complemtaresem -saude-pics-na-assistencia-ao-tratamento acesso em 14/08/2020

CORRÊIA, B. M.; SCHOTTEN, L. A.; MARCHADO, M. Aromaterapia na saúde e na beleza: Desenvolvimento de um manual prático. Trabalho de conclusão de curso I. Universidade do Vale do Itajaí - UNIVALE, Florianópolis, Santa Catarina- 2010.

Covid-19: CNS recomenda divulgação de Práticas - Conass, disponível em $<$ www.conass.org. $b r>$ covid-19-cns-recomenda-divulga...> acesso em 14/08/2020

CHUA, S.E., CHEUNG, V., CHEUNG C., et al. Psychological effects of the SARS out break in Hong Kong on high-risk health care workers. Can J Psychiatry. 2004;49(6):391393.doi:10.1177/070674370404900609

DACAL, M.del P. O, SILVA, I.S., Impactos das práticas integrativas e complementares na saúde de pacientes crônicos.Revista saúde debate | rio de janeiro, v. 42, n. 118, p. 724-735, jul-set 2018

Danzmann, P.S; Silva A.C.P; Guazina, F.M.N.; Atuação do psicólogo na saúde mental da população diante da pandemia. J. nurs. health. 2020.

DIAS, P.C.M.S.; Utilização de produtos naturais em aromaterapia.; Dissertação apresentada ao Instituto Politécnico de Bragança e à Universidade de Salamanca para obtenção do grau de mestre em Farmácia e Química de Produtos Naturais, Bragança 2013.; Disponível em: acesso em 19/10/20

Li, Z., Ge, J., Yang, M., Feng, J., Qiao, M., Jiang, R., ...\& Yang, C. (2020b). Vicarious traumatization in the general public, members, and non-members of medical teams aiding in COVID-19 control Brain, Behavior, and Immunity. https://doi.org/10.1016/j.bbi.2020.03.007 
MACHADO B. F. M. T.; Ary Fernandes Jr, A.; Óleos Essenciais: Aspectos Gerais e usos em Terapias Naturais. Cad. acad., Tubarão, v. 3, n. 2, p. 105-127, UNISUL 2011. Dissertação apresentada ao Instituto Politécnico de Bragança e à Universidade de Salamanca para obtenção do grau de mestre em Farmácia e Química de Produtos Naturais, Bragança 2013

Moeini, M; Khadibi, M; Bekhradi, R; Effect of aromatherapy on the quality of sleep in ischemic heart disease patients hospitalized in intensive care units of heart hospitals of the Isfahan University; - Iranian journal of , 2010.

MULYANINGSIH, S.; SPORER, F.; REHLING, ].; WINK, M. Antibacterialactivity Of essential oils from eucalyptus and of selected components against multidrug-resistant bacterial pathogens. Pharm. Biol. 2011, 49(9), 893-9. Doi: 10.3109/13880209.201 1.553625. Dispon \{velem:

<www.ncbi.nlm.nih.gov/pubmed/2 $1591991>$.

NASCIMENTO, A.; Prade A.C.K.;Aromaterapia para o autocuidado em tempos de coronavírus; Especial Cuidado integral na Covid-19 Número 2.; Recife Fiocruz PE;2020.

ORNELL, F., Schuch, J. B., Sordi, A. O., \& Kessler, F. H. P. (2020). "Pandemic fear" and COVID-19: Mental health burden and strategies. Brazilian Journal of Psychiatry. Acesso 12/03/2020, de https://www.rbppsychiatry.org.br/details/943/en-US/-pandemic-fear--andcovid-19--mental-health-burden-and-strategies

PRADE, A.C.K. As plantas aromáticas na pandemia de Covid-19: um olhar nos preparos ancestrais; Especial Cuidado integral na Covid-19 Número 2.; Recife Fiocruz PE;2020

SARTÓRIO, C.L.; e col. Paradoxos de Retroalimentação da Pandemia da COVID-19: quebrando o ciclo. Universidade Federal do Espírito Santo, Vitória, ES, Brasil;2020.

SAHARKHIZ, M.J.; MOTAMEDI, M.; ZoMORODIAN, K.; PAKSHIR, K.; MIRI, R.; HEMYARI, K. Chemical Composition, Antifungiland Antibiofilm Activities Of the Essential Oil of Mentha piperitaL. ISRN Pharmaceutics2012, ID 718645. Doi: 10.5402/2012/718645. Disponível em: <http://downloads.hindawi.com/journals/isrn.pharmaceutics/2012/718645. pdf $>$.

SCHMIDT, B. et al; Impactos na Saúde Mental e Intervenções Psicológicas Diante da Pandemia do Novo Coronavírus (COVID-19). Revista Estudos de Psicologia (Campinas), na Seção Temática: "Contribuições da Psicologia no Contexto da Pandemia da COVID-19". 2020.

SCHMIDT, Beatriz; et al. Impactos na saúde Mental e Intervenção Psicológicas diante d Pandemia do Novo Cornavírus ( COVID-19). Manuscrito submetido à Revista Estudos de Psicologia (Campinas), na Seção Temática: "Contribuições da Psicologia no Contexto da Pandemia da COVID-19".

SCHNITZLER, P.; SCHON, K.; REICHLING,]. Antiviral activity of Australian Tea tree oil and eucalyptus oil agains therpes simplex virusin cell culture. Die Pharmazie 2001, 56(4), 343-347. Disponivelem: <http://europepmc.org/abstract/med/1 1338678>.

SCHUHMACHER, A.; REICHLING, J.; SCHNITZLER, P. Virucidal effect of peppermint 


\section{SOMANLU: Revista de Estudos Amazônicos - UFAM ISSN (impresso): 1518-4765/ ISSN (eletrônico): 2316-4123}

ANO 20, no 2, Jul./Dez. 2020

Oil Mentha piperita on the enveloped viruses herpes simplex virus type 1 and type 2 in vitro. Phytomedicine 2003, 10(6-7),

504-510.

Disponível

em:

$<$ www.ncbi.nlm.nih.gov/pubmed/13678235>. 